\title{
A Systematic Review of the Effectiveness of Videoconference-Based Tele-Education for Medical and Nursing
}

\section{Education}

\begin{abstract}
Background: Rural nurses and doctors typically have little opportunity to further their education and training. Studies have shown high participant satisfaction with the use of educational technology, such as videoconferencing, for education. A review of effectiveness of videoconference-based tele-education for medical and nursing education was conducted.
\end{abstract}

Aims: The aims of this study were to: (1) systematically review the literature and critique the research methods on studies addressing the review question: "How effective is videoconference-based education for the education of doctors and nurses?" (2) summarize the existing evidence on the effectiveness of videoconference education for medical and nursing staff; and (3) apply the findings to South Africa and other countries across the globe.

Methods: Research citations from 1990 to 2011 from cumulative index of nursing and allied health literature, Medline, Pubmed, Psyclnfo, EBSCOhost, SABINET, Cochrane Database of Systematic Reviews, the Cochrane Controlled Trial Registry, Database of Abstracts of Reviews of Effectiveness, unpublished abstracts through NEXUS and Internet search engines (Google/Google scholar) were searched. Review methods included searching, sifting, abstraction, and quality assessment of relevant studies by two reviewers. Studies were evaluated for sample, design, intervention, threats to validity, and outcomes. No meta-analysis was conducted as the studies provided heterogeneous outcome data.

Results: Five studies were reviewed. Videoconference and face-to-face education is at least equivalent and one study reported an increase in knowledge and knowledge integration.

Recommendations: Despite the methodological limitations and heterogeneity of the reviewed studies, there appears to be sufficient evidence of effectiveness to provide a rigorous Grade B evidence-based recommendation of moderate support.

Conclusions: The use of videoconferencing for nursing and medical education should be encouraged along with guidelines for the use of videoconferencing. The paucity of studies and the lack of empirical precision in evaluating effectiveness of these interventions necessitate future rigorously designed experimental studies.

KEYWORDS: videoconference, distance education, medical education, nursing education, systematic review 
Jennifer Chipps, Lecturer, School of Nursing, University of KwaZulu-Natal, Durban, South Africa; Petra Biysiewicz, Professor, School of Nursing, University of KwaZulu- Natal, Durban, South Africa; Maurice Mars, Professor and Head of Department of TeleHealth, University of KwaZulu-Natal, Durban, South Africa

Address correspondence to Jennifer Chipps, University of KwaZulu-Natal, 75th Anniversary Avenue, Glenwood Durban, Durban, KwaZulu-Natal 4000, South Africa; chipps@ukzn.ac.za

\section{INTRODUCTION}

In South Africa, like most middle and lower income countries, health services in rural areas have difficulty recruiting and retaining nursing and medical staff. Rural nurses and doctors have traditionally had little access to continuing education and training as well as the support of mentors or specialists. International and local studies have showed high participant satisfaction with the use of educational technology such as videoconferencing (D'Souza 2000; Hadley \& Mars 2008; Chipps 2010) and videoconference-based education has been identified as a strategy to reduce some of the disincentives of rural practice (D'Souza 2000).

The use of videoconferencing for postgraduate continuing medical education in South Africa is not new and has been successfully sustained (Mars 2007a). However, videoconference-based education for nurses and doctors is not part of routine medical education and the evidence base in education has not yet been well established. Videoconference-based education in rural state hospitals in South Africa is also hindered by low bandwidth and poor access to technology. The aim of this study was to conduct a systematic review of the effectiveness of videoconference- based education to doctors and nurses in rural areas.

\section{BACKGROUND}

Videoconference-based education is the use of communication technology, such as phone lines (integrated services digital network [ISDN]) or the Internet (Internet protocol [IP]) to provide education from a central site to remote distant sites using live interactive audio-video communication. There are a wide range of video systems in use and they vary in terms of costs and resolution of video images. The videoconferencing systems also range from video cameras at both ends of the communicating sites, personal computers with video monitors and high-speed communication networks, or small video cameras at both sites, which then connect to television receivers (Ball et al. 1996). For the purpose of this review, live synchronous videoconference-based education is defined as education using videoconference equipment to provide teaching or training to remote participants with live visual and verbal interaction between teachers and participants (Curran 2006).

Examples of educational activities in medical and nursing education using videoconferencing include undergraduate education (Callas et al. 2004), resident education (O'Regan et al. 2010), journal clubs (Ahn et al. 2007), ward rounds (Allen et al. 2002, 2007; Cunningham \& Van der Merwe 2009; Gray et al. 2009), continuing medical education (Allen et al. 2002; Fitzgerald et al. 2002; Karlinsky et al. 2006), and clinical supervision (Xavier et al. 2007).

The main outcomes reported in these studies include participant satisfaction, the occurrence of technical issues such as poor quality of picture and sound, and the general perceptions and attitudes of participants to videoconference-based education. Overall, participants in these studies reported high levels of satisfaction with the use of videoconferencing, with only a few reports of technical problems that were experienced.

The University of KwaZulu-Natal Medical School in South Africa has conducted videoconference-based education in a number of medical disciplines since 2001 (Mars 2007a). In 2010, there were 35 postgraduate academic programs being delivered via videoconferencing, broadcasting over 1,430 hours of interactive teaching to up to eight sites simultaneously (Mars 2011). An evaluation of the videoconference-based teaching to pediatric surgery residents indicated universal satisfaction with videocon- ference teaching from those teaching and from the participants at the distant sites (Hadley \& Mars 2008). Since 2008, the University of KwaZulu-Natal School of Nursing also commenced outreach education to rural midwives using videoconferencing. These evaluations showed that the course was successfully implemented with potential savings of time and money and high participant satisfaction (Chipps 2010).

\section{AIMS}

The aims of the study were to: (1) systematically review the literature and critique the research methods on studies addressing the review question: "How effective is videoconference-based education for the education of doctors and nurses?" (2) summarize the existing evidence on the effectiveness of videoconference education for medical and nursing staff; and (3) apply the findings to South Africa. In doing so, empirically tested videoconference- based education may be supported for nursing and medical education, specifically for isolated health workers.

\section{METHODOLOGY}

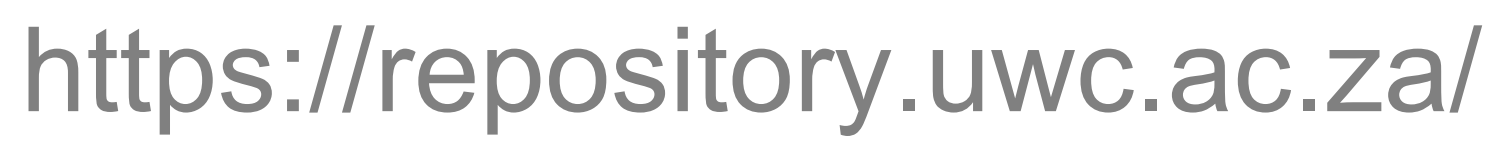


A systematic review of the literature was carried out to retrieve international and national studies on the effectiveness of videoconferencing. Effectiveness relates to the outcomes of educational activity (Belfield et al. 2001) and was defined as objective measures demonstrating no difference between videoconference-based and traditional face- to-face education outcomes of knowledge and skills.

\section{Search Criteria}

The search strategy was designed to access both published and unpublished materials from the last 10 years. However, because of the paucity of studies measuring effectiveness, the search was increased to 22 years (19902011). A limited search of the cumulative index of nursing and allied health literature (CINAHL) and Medline was initially undertaken to identify relevant keywords contained in the title, abstract, and subject descriptors. The reviewers then identified Medical Subject Headings (MESH) terms and the synonyms used by respective databases, which were then used in an extensive search of the literature. The search terms used were: videoconferencing or telecommunications, education or training or undergraduate or postgraduate or in-service or continuing education or "continuing education," medical or nursing evaluation studies or randomized controlled trials or experimental studies or quasi-experimental studies or evaluation studies, and 1990 to present. The following databases were searched using the search terms: CINAHL, Med- line, Pubmed, Psyclnfo, EBSCOhost, SABINET, Cochrane Database of Systematic Reviews, the Cochrane Controlled Trial Registry, Database of Abstracts of Reviews of Effectiveness, unpublished abstracts through NEXUS and Internet search engines (Google/Google scholar). The reference lists of key articles reviewed were searched and appropriate articles identified and accessed. No searching of gray literature such as such as non-commercially published reports, working papers, theses, and conference proceedings, were conducted.

The type of studies considered for inclusion in this review were those in which: (1) the participants were medical or nursing students or qualified doctors or nurses (including multidisciplinary groups which were predominantly doctors and nurses); (2) the intervention described was live synchronous videoconference-based education or training using either ISDN or IP connections; (3) the outcomes focused on effectiveness (equivalence of knowledge and skills transfer between face-to-face and videoconferencing); and (4) studies were high-quality evaluation studies with two group comparisons (including randomized controlled trials, quasi-experimental studies, and two group evaluation studies). Only articles in English and Afrikaans and articles published from 1990 onward were included.

Exclusion criteria were: (1) study participants from fields other than nursing or medicine, such as pharmacy, veterinary science, and health sciences; (2) interventions other than live videoconferencing such as streaming video, web-based online teaching, and asynchronous videocon- ference; and (3) studies with satisfaction as an outcome measure. Even though most studies generally reported that satisfaction was high for videoconference-based education, satisfaction was not included as an outcome measure for this study. There is debate as to how satisfaction is measured and the validity of the concept of satisfaction as a measure of effectiveness. Belfield et al. (2001) stated that satisfaction can at best be a crude proxy for the substantive effects of education (Belfield et al. 2001).

\section{Review Process and Data Abstraction}

The review process was conducted in four stages. First, the titles and abstracts of articles identified were independently screened for relevance by two reviewers. For studies where the title or abstract did not provide sufficient information or the reviewers disagreed, the full article was retrieved for review. Any further disagreements were discussed and referred to the third reviewer.

Second, the retrieved articles were reviewed for suitability for inclusion for full article review based on the type of an evaluation design. Eligibility for full article review and assessment of study characteristics were extracted and entered into Excel. A Kappa statistic was calculated to assess the level of agreement for eligibility for inclusion. Third, full article review and extraction was conducted using an electronic review format in Excel based on guidelines for intervention studies to systematically evaluate the methodological rigor of the eligible articles (National Health and Medical Research Council [NHMRC] 1999). For each eligible study, author, journal, publication year, the type of setting (e.g., medical or nursing), the type of profession (e.g., midwives), number of participants (including loss to follow-up), the outcomes, the comparison groups (consistent treatment, standard outcomes, and adequate), and study design (sampling, before and after measurement, appropriate statistics) were extracted.

The quality and methodological rigor of studies were evaluated using the adapted Oxford Evidence Based Levels (Oxford Centre for Evidence-Based Medicine 2001) and classified from I to V (Table 1). Based on the recommendations of the NHMRC (1999a) that strength of evidence entails aspects of studies other than study design, factors such as bias, statistical significance of results, and relevance of evidence also were taken into consideration (NHMRC 1999).

$$
\text { https://repository.uwc.ac.za/ }
$$


TABLE 1

Adapted levels of evidence and grades of recommendations

(National Health and Medical Research Council [NHMRC], 1999)

\begin{tabular}{|c|c|c|}
\hline LOE & $\begin{array}{l}\text { LEVEL OF EVIDENCE } \\
\text { (EFFECTIVENESS) }\end{array}$ & $\begin{array}{c}\text { GRADES OF } \\
\text { RECOMMENDATIONS }\end{array}$ \\
\hline 1 & $\begin{array}{l}\text { Systematic reviews or big } \\
\text { randomized controlled } \\
\text { trial (RCT) }\end{array}$ & A \\
\hline II & $\begin{array}{l}\text { Well designed RCT or } \\
\text { experimental designs }\end{array}$ & $\begin{array}{l}\text { B (including extrapolations } \\
\text { of level I studies) }\end{array}$ \\
\hline Illa & $\begin{array}{l}\text { Well designed } \\
\text { quasi-experimental } \\
\text { studies }\end{array}$ & $\mathrm{B}$ \\
\hline IIllb & $\begin{array}{l}\text { Comparative studies } \\
\text { (allocation not random } \\
\text { or time series) }\end{array}$ & \\
\hline IIIc & $\begin{array}{l}\text { Comparative studies } \\
\text { (historical control, } \\
\text { parallel group) }\end{array}$ & \\
\hline IV & $\begin{array}{l}\text { Case studies or series } \\
\text { with posttest reports }\end{array}$ & $\begin{array}{l}C \text { (including extrapolations } \\
\text { of level II studies) }\end{array}$ \\
\hline V & Surveys & $\begin{array}{l}\text { D (including troubling or } \\
\text { inconsistent studies at } \\
\text { any level) }\end{array}$ \\
\hline
\end{tabular}

Bandwidth has been found to be a moderator in videoconference-based interventions and evidence grading normally includes classification of bandwidths (Hyler et al. 2005). In this study, bandwidth is not included as continuing medical education in South Africa has been successfully implemented at the lowest (128 kbps) bandwidth (Mars 2007b; Chipps 2010).

Finally, all studies included were randomized clinical trials (RCTs), trials, or high-quality experimental studies. The remaining studies were subjected to detailed extraction and classification of quality as high, moderate, or poor. Study quality criteria were: (1) information on the setting; (2) information on the participants; (3) detailed intervention description, including bandwidth of videoconference transmission; (4) randomization to concurrent and control groups; (5) blind allocation of participants and staff; (6) reported inclusions and exclusions; and (7) reported effect size of the intervention.

\section{RESULTS}

Three hundred twelve article abstracts were retrieved based on the refined search terms (Figure 1). Of these, 238 relevant abstracts on videoconferencing and medical or nursing education were reviewed for suitability based on study design. There was good agreement between reviewers with a Kappa 0.8 (95\% CI 0.7-0.9). The reviewers identified 115 evaluation studies suitable for review with the two most common reasons for exclusion being no or poor evaluation methodology, or descriptive case study evaluations.

An analysis of the 115 evaluation studies showed that $82 \%$ were published after 2000 and $58 \%$ were on medical education (Table 2). In these studies, the educational sessions varied ranging from single training sessions to weekly sessions and the videoconference format was not often reported. When the videoconference format was reported, it was either IP based or using ISDN lines with the lowest bandwidth being ISDN $128 \mathrm{kbps}$. All of the studies measured different education outcomes using different tools.

Twenty-nine studies of level III or above (experimental or quasi-experimental studies) yielded data for videoconference-based education programs for doctors and nurses. Exclusions included level IV and level V studies with either no comparison groups or interventions and outcomes not clearly described. Using Excel to capture and grade the extracted data, 22 of the 29 level III and 


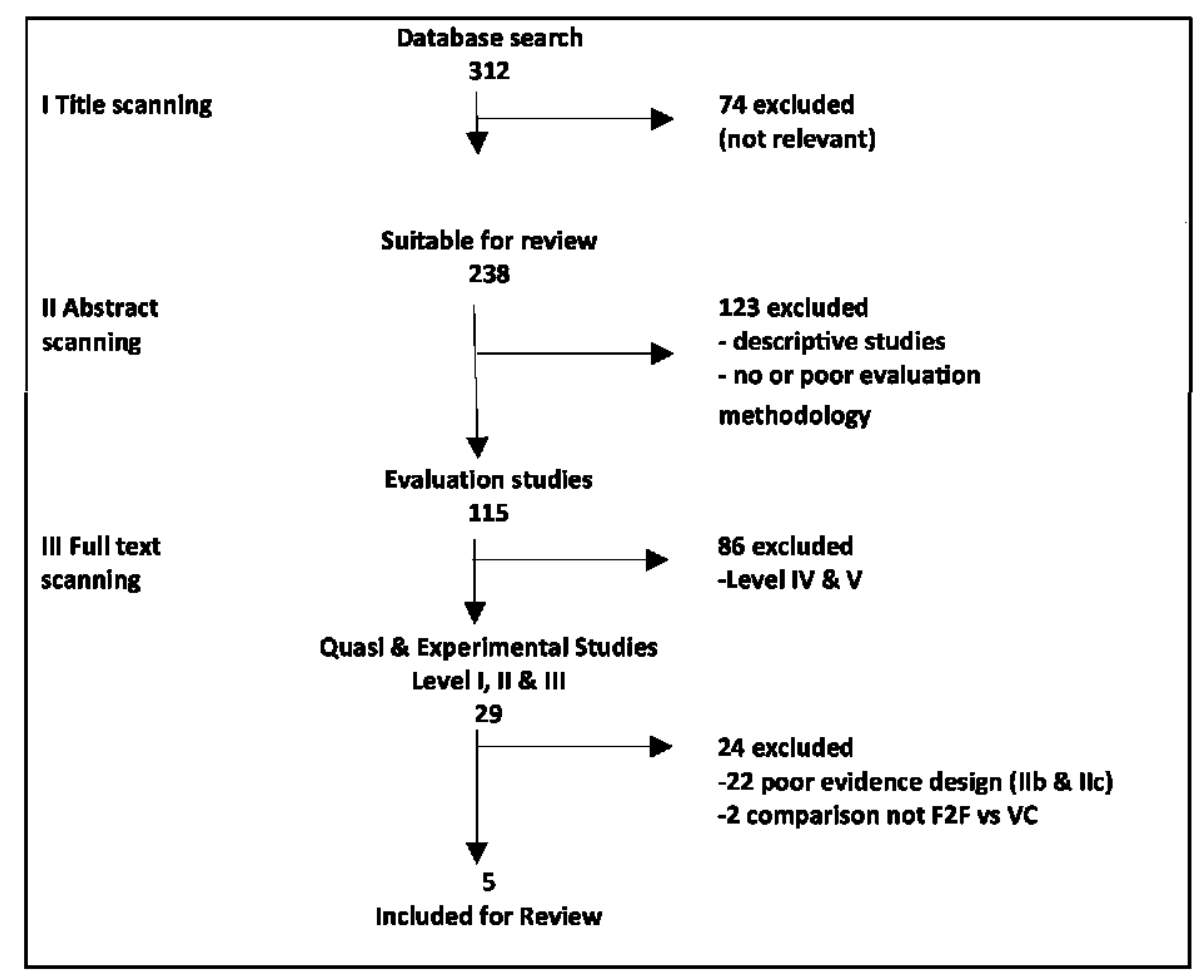

Figure 1. Article retrieval process.

\begin{tabular}{|c|c|}
\hline Date of publication & Number $(\%)$ \\
\hline $1990-2000$ & $20\langle 17 \%\rangle$ \\
\hline $2001-2005$ & $43\langle 37 \%\rangle$ \\
\hline $2006-2011$ & $52(45 \%)$ \\
\hline Participant group & No $\langle \%\rangle$ \\
\hline Medicine & $68\langle 59 \%\rangle$ \\
\hline Nursing & $21(18 \%)$ \\
\hline $\begin{array}{l}\text { Multidisciplinary (including both } \\
\text { medical and nursing as the } \\
\text { dominant groups) }\end{array}$ & $26(22 \%)$ \\
\hline Study design & No $\langle \%\rangle$ \\
\hline RCT (II) & $4\langle 3 \%\rangle$ \\
\hline Experimental (crossover design; III) & $4(3 \%)$ \\
\hline Quasi-experimental (III) & $21(18 \%)$ \\
\hline Dther (IV) & $86(74 \%)$ \\
\hline
\end{tabular}

above studies were excluded because of poor evidence design (nonrandomization and using existing convenient groups), satisfaction as an outcome measure, and methodological rigor. A further two studies of the same groups (Locatis et al. 2010, 2011) were excluded as the main comparison was between colocated and dispersed students all attending videoconferencing. This left five experimental studies of moderate to good methodological quality to be reviewed. The planned meta-analysis of these studies was not performed as it was not possible to quantitatively combine the outcome of the studies.

\section{Studies for Review}

There are few quality intervention studies on this topic with only five studies (Table 3) meeting the criteria for inclusion in this review (van Boxell et al. 2003; Seibert et al. 2004a; Stain et al. 2005a; Bertsch et al. 2007; Weeks \& Molsberry 2008).

Design. The studies included were three experiments of moderate quality (van Boxell et al. 2003; Seibert et al. 2004b; Bertsch et al. 2007), one clinical trial of moderate quality (Stain et al. 2005a) and one RCT of good quality (Weeks \& Molsberry 2008). All of the studies included a control group, but the experimental studies used crossover designs. Only two studies included before and after ratings (van Boxell et al. 2003; Weeks \& Molsberry 2008).

$$
\text { https://repository.uwc.ac.za/ }
$$


Sample. All of the studies, except Bertsch etal. (2007), had small samples, with only Weeks \& Molsberry (2008) and Bertsch et al. (2007) providing information on sample power and loss to follow-up (Bertsch et al. 2007; Weeks \& Molsberry 2008). Studies did not randomly select participants, although all studies except Bertsch et al. (2007) randomized the participants into intervention and control groups, making randomization the most common method of allocation to groups. No blind allocation was possible as participants were aware of which modality they were using.

Interventions. The studies included different forms of medical and nursing education provided by both face-to- face and videoconferencing. Connections were via ISDN or IP with bandwidth ranging from 128 to 768 kbps. Content ranged from ongoing in-service sessions, 8-hour retraining sessions to 1-hour lectures. Interventions included undergraduate, postgraduate, and in-service training.

Outcomes. Although the studies reported the use of different instruments and statistical methods, the most commonly reported outcome in all the studies was "knowledge" in terms of tests taken by the participants based on the contents of the course, with one study measuring psy- chomotor skills (Weeks \& Molsberry 2008). Four of the studies cited no inferiority of videoconference-based education to other modes in scoring knowledge and a small study indicated an increase in knowledge (Seibert et al. 2004b). In the studies, differences between groups were measured using relevant parametric and nonparametric tests and statistical significance testing with $p$ values.

A number of issues that may affect outcomes were highlighted in the reviewed studies. These included learners preferring face-to-face teaching in some situations (van Boxell et al. 2003), at times having practical technical difficulties (van Boxell et al. 2003), and the importance of interaction during the education sessions (Seibert et al. 2004b).

\section{DISCUSSION}

\section{Threats to the Validity of the Review}

Study design. Most of the evidence available was from studies of moderate quality, which could have introduced biases that can lead to over- and underestimates of intervention effectiveness (Cook et al. 1997). Of the 29 level III and above studies, two studies, on closer examination, did not compare videoconference-based teaching with face-to- face teaching. Twenty-two studies were of poor quality with small samples and either no randomized allocation to intervention and control groups. Control selection in these studies often occurred through convenience sampling of the videoconference and face-to-face sites. This raised the issue of what constitutes a comparison group in evaluation of videoconference-based education and whether describing the evaluation of a "program" that includes two groups (a videoconference and a face-to-face site) qualifies as "two comparison groups." To decrease the threat to validity, 
TABLE 3

Characteristics of the five experimental studies included in the review

\begin{tabular}{|c|c|c|c|c|c|c|c|}
\hline $\begin{array}{l}\text { AUTHOR } \\
\text { (YEAR) }\end{array}$ & PARTICIPANTS & INTERVENTION & CONNECTION & STUDY DESIGN & $\begin{array}{c}\text { ASSESSMENT } \\
\text { OF } \\
\text { OUTCOMES } \\
\text { TOOL }\end{array}$ & OUTCOMES & $\begin{array}{l}\text { LEVEL AND } \\
\text { QUALITY OF } \\
\text { EVIDENCE }\end{array}$ \\
\hline $\begin{array}{l}\text { van } \\
\text { Boxell } \\
\text { et al. } \\
\text { (2003b) }\end{array}$ & $\begin{array}{l}\text { Palliative care } \\
\text { nurses } \\
\text { Pain, physical } \\
\text { symptom, } \\
\text { psychological } \\
\text { symptoms, } \\
\text { loss }\end{array}$ & $\begin{array}{l}49 \text { Palliative } \\
\text { care } \\
\text { education } \\
\text { workshops } \\
\text { I: VC } \\
\text { C: F2F }\end{array}$ & ISDN 128 kbps & $\begin{array}{l}\text { Randomized } \\
\text { crossover (x4) } \\
\text { I: } V C n=10 \\
\text { C: } F 2 F n=10\end{array}$ & $\begin{array}{l}\text { Short answer } \\
\text { tests }\end{array}$ & $\begin{array}{l}\text { Knowledge } \\
\qquad \begin{array}{r}\text { ns } \\
I=\uparrow 17 \% \\
C=\uparrow 18 \%\end{array}\end{array}$ & $\begin{array}{l}\text { Level Illa } \\
\text { Moderate } \\
\text {-S small } \\
\text {-RA } \\
\text {-BA } \\
\text {-no B }\end{array}$ \\
\hline $\begin{array}{l}\text { Seibert } \\
\text { et al. } \\
(2004 \mathrm{~b})\end{array}$ & $\begin{array}{l}\text { Clinical nurse } \\
\text { specialist } \\
\text { postmasters } \\
\text { Simulated } \\
\text { patient and } \\
\text { case studies }\end{array}$ & $\begin{array}{l}14 \text { week } \\
\text { advanced } \\
\text { health } \\
\text { assessment } \\
\text { (6 weeks } \\
\text { testing VC } \\
\text { intervention) } \\
\text { I: VC } \\
\text { C: F2F }\end{array}$ & Not stated & $\begin{array}{l}\text { Randomized } \\
\text { crossover (x2) } \\
\text { I: } \mathrm{VC} n=6 \\
\text { C: } \mathrm{F} 2 \mathrm{~F} n=6 \\
\text { Then } \\
\text { crossover } \\
\text { I: } \mathrm{VC} n=6 \\
\text { C: } \mathrm{F} 2 \mathrm{~F} n=6\end{array}$ & $\begin{array}{l}\text { Topic } \\
\text { knowledge } \\
\text { with } \\
\text { computer- } \\
\text { based } \\
\text { multiple } \\
\text { choice, } \\
\text { True/false } \\
\text { and matching } \\
\text { Topic } \\
\text { integration } \\
\text { Short } \\
\text { answers }\end{array}$ & 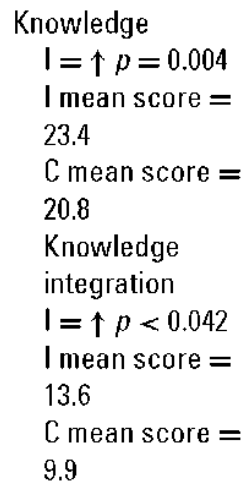 & $\begin{array}{l}\text { Level Illa } \\
\text { Poor } \\
\text {-S small } \\
\text {-RA } \\
\text {-no BA } \\
\text {-no B }\end{array}$ \\
\hline $\begin{array}{l}\text { Stain } \\
\quad \text { et al. } \\
\text { (2005b) }\end{array}$ & $\begin{array}{l}\text { Third-year un- } \\
\text { dergraduate } \\
\text { surgical } \\
\text { clerkship } \\
\text { Orthopedics, } \\
\text { urology, oph- } \\
\text { thalmology, } \\
\text { otolaryngol- } \\
\text { ogy, } \\
\text { neurosurgery, } \\
\text { plastic } \\
\text { surgery }\end{array}$ & $\begin{array}{l}\text { Subspecialty } \\
\text { lectures (6 } \\
\text { hours /week, } \\
\text { 4-week } \\
\text { rotation) } \\
\text { I:VC } \\
\text { C: F2F } \\
\end{array}$ & ISDN $128 \mathrm{kbps}$ & $\begin{array}{l}\text { RCT } \\
\text { Two groups } \\
\begin{array}{l}I=12 \\
C=98\end{array}\end{array}$ & $\begin{array}{l}\text { Weekly quizzes } \\
\text { Percentage } \\
\text { correct }\end{array}$ & $\begin{array}{l}\text { Knowledge tests } \\
\leftrightarrow \text { ns } \\
\text { I mean score }= \\
70.5 \% \\
\text { C mean score }= \\
71.4 \% \\
\text { Total score } \\
\leftrightarrow \text { ns }\end{array}$ & $\begin{array}{l}\text { Level II } \\
\text { Moderate } \\
\text {-S small (I) } \\
\text {-RA } \\
\text {-no BA } \\
\text {-no B }\end{array}$ \\
\hline $\begin{array}{l}\text { Bertsch } \\
\text { et al. } \\
\text { (2007b) }\end{array}$ & $\begin{array}{l}\text { Third year } \\
\text { medical } \\
\text { students } \\
\text { Diabetes, skin } \\
\text { lesions, } \\
\text { fatigue, chest } \\
\text { pain, joint } \\
\text { pain }\end{array}$ & $\begin{array}{l}\text { Eight two-hourly } \\
\text { weekly } \\
\text { lectures } \\
\text { I: VC } \\
\text { C: F2F } \\
\end{array}$ & Not stated & $\begin{array}{l}\text { Crossover } \\
\text { I: } \mathrm{VC} n=52 \\
\text { C: } \mathrm{F} 2 \mathrm{~F} n=52\end{array}$ & $\begin{array}{l}\text { Learning } \\
\text { objectives by } \\
\text { clinical } \\
\text { practice } \\
\text { exam }\end{array}$ & $\begin{array}{l}\text { Knowledge } \\
\leftrightarrow \text { ns } p=0.66 \\
\text { I mean score }= \\
76 \% \\
C \text { mean score }= \\
78 \%\end{array}$ & $\begin{array}{l}\text { Level IIIb } \\
\text { Moderate } \\
\text {-S fair } \\
\text {-non RA } \\
\text {-no BA } \\
\text {-no B }\end{array}$ \\
\hline
\end{tabular}


Table 3

\begin{tabular}{|c|c|c|c|c|c|c|c|}
\hline $\begin{array}{l}\text { AUTHOR } \\
\text { (YEAR) }\end{array}$ & PARTICIPANTS & INTERVENTION & CONNECTION & STUDY DESIGN & $\begin{array}{c}\text { ASSESSMENT } \\
\text { OF } \\
\text { OUTCOMES } \\
\text { TOOL }\end{array}$ & OUTCOMES & $\begin{array}{l}\text { LEVEL AND } \\
\text { OUALITY OF } \\
\text { EVIDENCE }\end{array}$ \\
\hline $\begin{array}{l}\text { Weeks \& } \\
\text { Mols- } \\
\text { berry } \\
\text { (2008b) }\end{array}$ & $\begin{array}{l}\text { Prehospital and } \\
\text { in-hospital } \\
\text { healthcare } \\
\text { workers (mul- } \\
\text { tidisciplinary) }\end{array}$ & $\begin{array}{l}\text { Pediatric } \\
\quad \text { Advanced } \\
\text { Life Support } \\
\text { (PALS) } \\
1 \text { day } \\
\text { retraining } \\
\text { I: VC } \\
\text { C: F2F }\end{array}$ & $\begin{array}{l}\text { IP/ISDN } \sim 512 \\
\text { kbps }\end{array}$ & $\begin{array}{l}\text { Prospective RCT } \\
\text { I: } V \mathrm{C} n=36 \sim \\
24 \\
\text { C: F2F } n=37 \\
\quad \sim 28\end{array}$ & $\begin{array}{l}\text { Written tests } \\
\text { Skills percent } \\
\text { proficiency } \\
\text { Confidence } \\
\text { rating } \\
\end{array}$ & $\begin{array}{l}\text { Knowledge } \\
\leftrightarrow \text { ns } p>0.10 \\
\text { Post } \\
\text { I mean }=95.6 \pm \\
4.5 \\
\text { C } \text { mean }=96.9 \pm \\
3.3 \\
\text { Follow-up } \\
\text { I mean }=91.8 \pm \\
5.9 \\
C \text { mean }=93.4 \pm \\
5.7 \\
\text { Skills } \\
\leftrightarrow \text { ns } p>0.10 \\
\text { Post } \\
\text { I mean }=98.1 \pm \\
3.1 \\
C \text { mean }=96.8 \pm \\
3.1 \\
\text { Follow-up } \\
\text { I mean }=88.8 \pm \\
9.4 \\
C \text { mean }=87.3 \pm \\
8.4 \\
\text { Confidence } \\
\leftrightarrow \text { ns } p>0.10 \\
\text { I mean }=8.3 \pm \\
1.6 \\
C \text { mean }=8.5 \pm \\
1.1\end{array}$ & $\begin{array}{l}\text { Level II } \\
\text { Good } \\
\text {-S fair } \\
\text {-RA } \\
\text {-B \& 2xA } \\
\text {-No B } \\
\end{array}$ \\
\hline
\end{tabular}

Note. $V C=$ videoconference; $F 2 F=$ face-to-face; $I=$ intervention; $C=$ control; $R S=$ random sample; $R A$ : random assignment; $S T=$ standard outcome tool; $B \& A=$ before and after measurement; $S=$ sample size; $B=$ blinding; $n s=$ not significant; ${ }^{\wedge}=$ equivalent $; \mid=$ decrease $;=$ increase.

These studies were excluded. Only five were experimental studies and they were small in size, had no blind allocation, and provided poor descriptions of videoconference connections or loss to follow-up.

Samples. Samples were small and underpowered. Although no random selection of participants occurred, all of the reviewed studies except one used randomized allocation to intervention and control groups.

Heterogeneity of participants. The heterogeneity in medical and nursing education participants may compromise the validity of the review. Even though it is recognized that education to pharmacists and dentists are not substantially different from those for nurses and doctors, to prevent further heterogeneity in the participants, studies on videoconference-based education in these groups were excluded.

Heterogeneity of study interventions. The reviewed studies were heterogeneous with different types of educational interventions and connectivity. Although the interventions were focused on increasing knowledge, the interventions were not standardized, nor did not follow any guidelines and they varied substantially. Only one study used a theoretical framework to deliver the intervention and this study showed an increase in knowledge in the intervention group (Seibert et al. 2004a). In addition, the reviewed studies did not include recommendations by bandwidth level because of the inconsistent reporting of videoconference equipment and bandwidth. 
Heterogeneity of outcomes. The validity of the review is compromised by the fact that, although all of the studies reported knowledge outcomes, these outcomes were not measured in a standard way. The studies used different assessment tools and tests that were not standardized or consistently converted to effect sizes. The sustainability of the results also was difficult to assess because of the lack of before and after tests and only one study providing data on follow up.

Data analysis. This systematic review was conducted following standard systematic procedures (Cook et al. 1997), but no statistical synthesis of the quantitative data could be conducted. The data were not extracted and combined because of the heterogeneity of study interventions and outcomes and poor methodological rigor.

Finally, the studies reviewed were mostly from the United States, with one from the United Kingdom, and another from Brazil. Therefore, their relevance for the South African context must be carefully considered.

\section{IMPLICATIONS FOR EDUCATION AND RESEARCH}

\section{Implications for Education}

The review supports the supposition of equivalence of videoconference and face-to-face education with one study reporting an increase in knowledge using videoconferencing and four studies reporting no significant difference in overall knowledge gain scores between the two modalities (level II-IIIb; van Boxell et al. 2003; Seibert et al. 2004b; Stain et al. 2005b; Bertsch et al. 2007; Weeks \& Molsberry 2008). One study assessed psychomotor skills and found no significant differences among delivery methods with this being sustained with both groups showed the same decline in knowledge and skill at 1 year (level II; Weeks \& Molsberry 2008).

The studies reviewed highlighted issues that may impact this review's findings, namely the preference for face-to-face teaching and the impact of technical problems and level of interaction on the positive outcome of videoconference-based teaching. Possible reasons for preferring face-to-face teaching may be that the face-to-face facilitator could possibly control the interaction, motivation, attention, and interest among participants better than during videoconferencing. This issue of interaction also is reported in satisfaction studies where distant participants rated their ability to participate in discussions lower than those at the presenting sites (Allen et al. 2007; Chipps 2010). In contrast, in studies where interaction was deliberately planned though the use of an engagement model (Seibert et al. 2004b; Stain et al. 2005b), the innovative use of videoconferencing significantly improved learning outcomes and performance motivation (Seibert et al. 2004b). Although the studies were limited by their small numbers of students, they demonstrated that engagement should be planned and integrated into videoconference-based teaching. In the trial of colocated and dispersed videoconferencing, Locatis et al. (2011) also showed that, when working collaboratively, synchronous communication at a distance via videoconference gave sufficient sense of presence so that the learning experience may be similar to that in actual classrooms (Locatis et al. 2011).

The effectiveness of videoconference-based teaching in the reviewed studies supports the need for new and innovative educational approaches to teaching with this medium (Kaufman \& Brock 1998; Seibert et al. 2004b; Stain et al. 2005b), adequate organizational time, and careful attention to audiovisual needs (Finley et al. 2001; Chipps 2010). Finley et al. (2001) further suggests that videoconference guidelines for presenters are needed.

\section{Recommendations}

Despite the methodological limitations and heterogeneity of the reviewed studies, there appears to be sufficient evidence for a Grade B recommendation of moderate support that nursing and medical educators should consider videoconference-based teaching as at least as effective as face-to-face to face teaching in terms of knowledge gains.

Even though further research is required in the use of videoconferencing for teaching clinical skills and the evidence for positive outcomes at different band- widths, clear guidelines and standard operating procedures will go a long way toward assisting educators in using this technology effectively.

\section{Implications for Future Research}

Although internationally there has been extensive descriptive research regarding the use of videoconferencing for education in medical and nursing education, there were few systematic empirical studies that have examined the effectiveness of these interventions.

Recommendations. Attempts to improve best practice in videoconference-based education should continue. Educators and researchers should: evaluate new technology in education using methodologically rigorous experimental studies with adequate sample sizes; include cost data; and focus on the specific context and needs of resource constrained countries, such as South Africa.

\section{https://repository.uwc.ac.za/}




\section{CONCLUSIONS}

The use of videoconferencing for nursing and medical education should be encouraged along with guidelines for the use of videoconferencing. The paucity of studies and the lack of empirical precision in evaluating effectiveness of these interventions necessitate future rigorously designed experimental studies.

\section{References}

Ahn H.H., KimJ.E., Ko N.Y., Seo S.H., Kim S.N. \& Kye Y.C. (2007). Videoconferencing journal club for dermatology residency training: An attitude study. Acta Dermato Venereologica, 87(5), 397-400.

Allen M., Mann K., Kells C., Ferrier S., O'Connor N. \& MacDonald P. (2007). Cardiology grand rounds: Effect of videoconferencing on educational value. Journal of Telemedicine and Telecare, 13(3), 136-141.

Allen M., Sargeant J. \& MacDougall E. (2002). Videocon- ferenced continuing medical education in Nova Scotia. Journal of Telemedicine and Telecare, 8(Suppl. 3), S3:2-4.

Allen M., Sargeant J., MacDougall E. \& O'Brien B. (2002). Evaluation of videoconferenced grand rounds. Journal of Telemedicine and Telecare, 8(4), 210-216.

Ball C.J., McLaren P.M. \& WatsonJ.P. (1996). Psychiatry: Communications technology and education in mental health. Journal of Telemedicine and Telecare, 2(Suppl. 1), 62-64.

Belfield C., Thomas H., Bullock A., Eynon R. \& Wall D. (2001). Measuring effectiveness for best evidence medical education: A discussion. Medical Teacher, 23(2), 164-170.

Bertsch T.F., Callas P.W., Rubin A., Caputo M.P. \& Ricci M.A. (2007). Effectiveness of lectures attended via interactive video conferencing versus in-person in preparing third-year internal medicine clerkship students for Clinical Practice Examinations (CPX). Teaching and Learning in Medicine, 19(1), 4-8.

Callas P.W., Bertsch T.F., Caputo M.P., Flynn B.S., Doheny-Farina S. \& Ricci M.A. (2004). Medical student evaluations of lectures attended in person or from rural sites via interactive videoconferencing. Teaching and Learning in Medicine, 16(1), 46-50.

Chipps J. (2010). The use of synchronous videoconferencing teaching to increase access to specialist nurse education in rural KwaZulu-Natal, South Africa. Knowledge Management \& E-Learning: An International Journal, 2(2), 154-168.

Cook D.J., Mulrow C.D. \& Haynes R.B. (1997). Systematic reviews: Synthesis of best evidence for clinical decisions. Academia and Clinic Annals, 126, 376-380.

Cunningham B.J. \& Van der Merwe R. (2009). Virtual grand rounds: A new educational approach in social work that benefits long-term care providers and patients in rural Idaho. Rural Remote Health, 9(1), 1073.

Curran V.R. (2006). Tele-education. [Background]. Journal of Telemedicine \& Telecare, 12(2), 57-63.

D'Souza R. (2000). A pilot study of an educational service for rural mental health practitioners in South Australia using telemedicine. Journal of Telemedicine \& Telecare, 6(Suppl.1), S187-S189.

Finley J.P., Beland M.J., Boutin C., Duncan W.J., Dyck J.D., Hosking M.C. \& Nykanen D. (2001). A national network for the tele-education of Canadian residents in pediatric cardiology. Cardiology in the Young, 11(5), 526-531.

Fitzgerald A., Bailey M., Smith A. C., Webb K., Keating D., Klepper K. \& Gibney E. (2002). Child development services: a multidisciplinary approach to professional education via videoconference. Journal of Telemedicine \& Telecare, 8(Suppl.3), S3:19-21.

Gray L.C., Wright O.R., Cutler A.J., Scuffham P.A. \& WoottonR. (2009). Geriatric ward rounds by video conference: A solution for rural hospitals. Medical Journal of Australia, 191(11-12), 605-608.

Hadley G.P. \& Mars M. (2008). Postgraduate medical education in paediatric surgery: Videoconferencing-a possible solution for Africa? Pediatric Surgery International, 24(2), 223-226.

Hyler S.E., Gangure D.P. \& Batchelder S.T. (2005). Can telepsychiatry replace in-person psychiatric assessments? A review and meta-analysis of comparison studies. CNS Spectrums, 10(5), 403-413.

Karlinsky H., Dunn C., Clifford B., Atkins J., Pachev G., Cunningham K., Fenrich P. \& Bayani Y. (2006). Workplace injury management: Using new technology to deliver and evaluate physician continuing medical education. Journal of Occupational Rehabilitation, 16(4), 719730.

Kaufman D.M. \& Brock H. (1998). Enhancing interaction using videoconferencing in continuing health education.

Locatis C., Berner E.S., Hammack G., Smith S., Maisiak R. \& Ackerman M. (2010). An exploratory study of colocation as a factor in synchronous, collaborative medical informatics distance education. BMC Research Notes, 3,30, e1-6.

Locatis C., Berner E.S., Hammack G., Smith S., Maisiak R. \& Ackerman M. (2011). Communication and proximity effects on outcomes attributable to sense of presence in distance bioinformatics education. $B M C$ Medical Education, 11, 10. doi:10.1186/1472-6920-11-10.

\section{https://repository.uwc.ac.za/}


Mars M. (2007a). Postgraduate medical education: Videoconferencing a possible solution for Africa. Paper presented at the IST-Africa Maputo, Mozambique, May 9-11, 2007.

Mars M. (2007b). Telemedicine in KwaZulu-Natal: From failure to cautious optimism. Journal ofTelemedicine and Telecare, 13(Suppl. 3), 57-59.

Mars M. (2012). Building the Capacity to Build Capacity in e-Health in Sub-Saharan Africa: The KwaZulu-Natal Experience. Telemedicine and e-Health, 18(1), 32-37.

National Health and Medical Research Council. (1999). How to use the evidence: assessment and application of scientific evidence, handbook series on preparing clinical practice guidelines. Canberra, Australia: NHMRC. Retrieved February 6, 2012, from au/_files_nhmrc/publications/attachments/cp69.pdf.

O'Regan K., Marsden P., Sayers G., Morrissey M., Hegarty H., Allen M., O'Connor O.J., Malone D. \& Maher M. (2010). Videoconferencing of a national program for residents on evidence-based practice: Early performance evaluation. Journal of the American College of Radiology, 7(2), 138-145.

Seibert D.C., GuthrieJ.T. \&AdamoG. (2004a). Improving learning outcomes: Integration of standardized patients \& telemedicine technology. Nursing Education Perspectives, 25(5), 232-237.

Stain S.C., Mitchell M., Belue R., Mosley V., Wherry S., Adams C.Z., Lomis K. \& Williams P.C. (2005a). Objective assessment of videoconferenced lectures in a surgical clerkship. American Journal of Surgery, 189(1), 8184.

Van Boxell P., Anderson K. \& Regnard C. (2003). The effectiveness of palliative care education delivered by videoconferencing compared with face-to-face delivery. Palliative Medicine, 4, 344-358. Retrieved from http://www.mrw.interscience.wiley.com/cochrane/clcen tral/articles/653/CN-00438653/frame.html.

Weeks D.L. \& Molsberry D.M. (2008). Pediatric advanced life support re-training by videoconferencing compared to face-to-face instruction: A planned non-inferiority trial. Resuscitation, 79(1), 109-117. Retrieved from http://www.mrw.interscience.wiley.com/ cochrane/clcentral/articles/o65/CN-00666065/frame. html.

Xavier K., Shepherd L. \& Goldstein D. (2007). Clinical supervision and education via videoconference: A feasibility project. Journal of Telemedicine \& Telecare, 13(4), 206-209. 